\title{
Evaluation of Intensive Care Patient Bed Cleanliness by ATP Bioluminescence
}

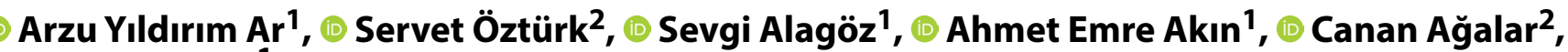 \\ Güldem Turan ${ }^{1}$ \\ ${ }^{1}$ Department of Anesthesiology and ICU, University of Health Sciences, Fatih Sultan Mehmet Health Application Research Center, \\ İstanbul, Turkey \\ ${ }^{2}$ Department of Infectious Diseases, University of Health Sciences, Fatih Sultan Mehmet Health Application Research Center, \\ İstanbul, Turkey
}

\begin{abstract}
Introduction: One of the most important causes of intensive care infections is cross-contamination, and priority is given to hand hygiene and environmental cleanliness in preventing it. Adenosine 5 triphospatebioluminescence (ATP) can measure the content of invisible contamination by measuring microorganism organic content. ATP produces results fast. In this study, we aim to evaluate the ATP measurement results retrospectively to observe environmental contamination at a time when infection rates have increased in our clinic.

Methods: We retrospectively evaluated the results of measurements performed on three different days in December 2017. The measurements were made when all 20 beds in our clinic were occupied. Measurements were made in a region of $5 \times 20$ $\mathrm{cm}$ on the side of each bed before and after cleaning using ATP Clean Trace (3M Company-USA) device, and the results were recorded in the relative light unit (RLU). Although there are studies that have adopted a surface cleanliness threshold of 100$500 \mathrm{RLU}$, in our clinic, we consider the most commonly used $250 \mathrm{RLU}$ for similar surface cleanliness as a threshold value. The threshold value for surface cleaning is accepted to be $250 \mathrm{RLU}$. If the value is above $250 \mathrm{RLU}$ after cleaning, the cleaning is repeated, and the measurements are made again.

Results: During the first measurement, three beds had to be cleaned a second time and during the third measurement, eight beds had to be cleaned a second time. Post-cleaning values were significantly lower than the pre-cleaning days $(p<0.05)$.

Discussion and Conclusion: Consistent with the literature, we found that satisfactory cleanliness of the sides of the bed, which we think have been cleaned visually, cannot be sometimes achieved and they required to be cleaned again. We believe that it is important to quantify cleanliness inspection in intermittent periods in the prevention of contamination in intensive care.
\end{abstract}

Keywords: Environment; infection control; intensive care unit; nosocomial infections.

Infection control and the environmental cleanliness of especially intensive care equipment are important in hospital infection management ${ }^{[1]}$. Cross-contamination is one of the most important causes of intensive care infections and hand hygiene and environmental cleanliness are predominant measures in its prevention. Contact with a contaminated environmental surface may lead to manual handling and spread of pathogens ${ }^{[2-4]}$. In this way, different agents have been isolated in contamination-induced infections ${ }^{[1]}$. 
Resilience, virulence, ease of transfer, ability to colonize or infect patients, biofilm formation capacity and tolerance capacity of pathogens to antiseptics, disinfectants, or surface materials are important in environmental contamination and spread of pathogens. Furthermore, many factors, such as effective and frequent cleaning of the environment, isolation facilities, hand hygiene and antimicrobial consumption, are effective in reducing environmental contamination ${ }^{[5]}$. Apart from the training of hospital staff in environmental cleaning, a system that will control the reliability of cleaning is required. Thus, visual assessment of the environment, microbial methods, fluorescent marker, ATP (Adenosine Triphosphate) bioluminescence methods are being used ${ }^{[5-7]}$.

ATP is present in all living cells. ATP is also an important building block in energy transfer reactions. ATP bioluminescence method can be defined as measuring the intensity of light emitted by enzymatic reactions. Bioluminescence is common in marine bacteria, fungi, some marine organisms, saltwater fish and fireflies in nature. The ATP bioluminescence method measures the presence of ATP on surfaces. This method is based on the reaction of ATP with the luciferin-luciferase enzyme to give bioluminescence light and measurement of this light by luminometer. On a standardized area, a sample is taken with a swap. Then, ATP reacts with luciferase to form Adenosine Monophosphate (AMP), which is measured with a bioluminometer and converted to numerical value as a relative light unit (RLU) $[6,8,9]$. This study aims to document and present the results of ATP measurement to observe environmental contamination at a time when infection rates have increased in our clinic.

\section{Materials and Methods}

Our intensive care clinic has 20 beds with a $100 \%$ occupancy rate. Health service providers are serving as shift workers from 08.00 to $16: 00$ and 16:00 to 08:00. Nine-ten nurses and three-four staff are employed during each shift period. Approval of the scientific studies board of our hospital (17073117-050.99) was obtained for this study. In our study, we retrospectively evaluated the results of ATP bioluminescence measurements that we performed on three different days in December 2017.

Before and after cleaning the same area of $5 \times 20 \mathrm{~cm}$ on the side edge of each bed we determined beforehand, with the disinfectant (40\% n-Alkyl Dimethyl Benzyl Ammonium Chloride, $60 \%$ Urea) that we use for the routine cleaning, measurements with ATP Clean Trace (3M Company-USA) instrument were made and recorded as RLU. The threshold value for surface cleaning is between 100-500 RLU. In our clinic, we consider the most commonly used 250 RLU as a threshold value for similar surface cleaning ${ }^{[2]}$. When the value above $250 \mathrm{RLU}$ was observed after cleaning, the cleaning was repeated and the measurement was renewed and recorded again.

\section{Statistical Analysis}

When evaluating the findings obtained in this study, IBM SPSS Statistics 22 for statistical analysis (SPSS IBM, Turkey) programs were used. While evaluating the study data, the suitability of the parameters to normal distribution was evaluated by the Shapiro-Wilks test and it was found that the parameters did not show normal distribution. Wilcoxon sign test was used for intragroup comparisons of the parameters before and after cleaning. Statistical significance was evaluated at $\mathrm{p}<0.05$.

\section{Results}

At the first measurement time, three beds had to be cleaned for the $2^{\text {nd }}$ time and at the $3^{\text {rd }}$ measurement time; eight beds had to be cleaned for the $2^{\text {nd }}$ time. On the first two measurement days, post-cleaning measurements were significantly lower than before cleaning $(p=0.000 ; p<0.05)$. On the third measurement day, post-cleaning values were also found to be lower $(p=0.001 ; p<0.05)$ (Table 1$)$.

Average 3-day values of the beds were found to be statistically significantly lower after cleaning than before cleaning $(p=0.000 ; p<0.05)($ Table 2$)$.

Table 1. Comparisons of the evaluations performed before and after cleaning performed on days 1, 2 and 3

\begin{tabular}{lccc}
\hline Measurement & $\begin{array}{c}\text { Pre-cleaning } \\
\text { Mean } \pm \text { SD } \\
\text { (median) }\end{array}$ & $\begin{array}{c}\text { Post-cleaning } \\
\text { Mean } \pm \text { SD } \\
\text { (median) }\end{array}$ & p \\
\hline $1^{\text {st }}$ & $332.5 \pm 456.7(200.5)$ & $67.9 \pm 60.1(45.5)$ & $0.000^{*}$ \\
$2^{\text {nd }}$ & $225 \pm 237.6(110)$ & $33.7 \pm 31.4(25)$ & $0.000^{*}$ \\
$3^{\text {rd }}$ & $638.1 \pm 709.6(322)$ & $129.5 \pm 70.8(114.5)$ & $0.001^{*}$ \\
\hline
\end{tabular}

Wilcoxon sign test; ${ }^{*} p<0.05$

Table 2. Mean values for the bed cleanliness before and after application of cleaning procedures

\begin{tabular}{lccc}
\hline & $\begin{array}{c}\text { Pre-cleaning } \\
\text { Mean } \pm \text { SD } \\
\text { (median) }\end{array}$ & $\begin{array}{c}\text { Post-cleaning } \\
\text { Mean } \pm \text { SD } \\
\text { (median) }\end{array}$ & p \\
\hline $\begin{array}{l}\text { Mean measurement } \\
\text { of three days }\end{array}$ & $398.5 \pm 379.4(344.6)$ & $77 \pm 25.8(74.8)$ & $0.000^{*}$ \\
\hline
\end{tabular}

Wilcoxon sign test; ${ }^{*} \mathrm{p}<0.05$. 


\section{Discussion}

In our intensive care unit, in the method we used retrospectively to check the cleanliness of the bed edges, we had to clean twice the edges of three beds in the first measurement and eight beds in the third measurement because the first measurements exceeded 250 RLU.

Huang et al. ${ }^{[10]}$ examined a total of 85 surfaces to evaluate the effectiveness of visual inspection, aerobic colony counts and ATP bioluminescence methods in surface cleanliness and reported that ATP bioluminescence test was a rapid and sensitive method for the control of cleanliness. They evaluated the sampling area as standard $100 \mathrm{~cm}^{2}$ on large surfaces, such as window sills, and sofas as in our study. They found the cut-off values for the ATP bioluminescence test as $5.57 \mathrm{RLU} / \mathrm{cm}^{2}$ for the aerobic colony counts as $<2.5$ $\mathrm{cfu} / \mathrm{cm}^{2}{ }^{[10]}$. In their study, Lewis et al. examined the biological load levels of four operating rooms cleaned with a new disinfectant as isopropyl alcohol/organofunctional silane solution and used the ATP bioluminescence method in their test. In their study, they examined a sampling surface of $2 \mathrm{~cm}^{2}$ and evaluated it as clean if $\leq 45 \mathrm{RLU}$, and dirty if $\geq 46 \mathrm{RLU}$ were found. They stated that they could differentiate between dirty and clean surfaces using the ATP bioluminescence method, but this method does not distinguish between microbial and non-microbial biological loads ${ }^{[11]}$. Richard et al. ${ }^{[12]}$ examined the degree of contamination of 13 different surfaces in six different orthopedic surgery operating rooms and have accepted 400-500 RLU values as clean according to previous publications about the hospital and restaurant industry. On the contrary, in our study, we accepted value of $250 \mathrm{RLU}$ to be more sensitive to the intensive care clinic. Although they did not evaluate the correlation of clinical infection with ATP bioluminescence method, they suggested that routine cleaning of places, such as bed heads, Bair Hugger buttons, or tourniquet machine buttons may be included in institutional cleaning protocols. In this study, we believe that failure to determine a sampling surface area is a limiting factor.

ATP bioluminescence method is used not only in hospital environmental cleaning but also in auditing cleaning in the food industry where hygiene is very important. Ayçiçek et al.'s study, they took 280 samples from 14 different surfaces of $10 \mathrm{~cm}^{2}$ in the hospital kitchen and compared the ATP bioluminescence method with traditional microbiological swab culture methods. They emphasized that the ATP bioluminescence method was rapid in assessing surface contamination, but could not replace culture methods and that the combination of both methods would be effective for monitoring surface cleanliness ${ }^{[13]}$.

In their study on 113 surfaces in the operating room and hospital clinics, Griffith et al. ${ }^{\text {[1] }}$ compared the visual examination, microbiological methods and ATP bioluminescence method. They suggested that there was no significant difference between microbiological methods and ATP bioluminescence where the visual evaluation was a poor indicator of cleaning efficiency compared to the other two methods, and also proposed an integrated cleaning monitoring program using ATP bioluminescence method together with visual and microbiological evaluations. Similarly, Cooper et al. evaluated visual evaluation, microbiological methods and ATP bioluminescence method before and after cleaning in two clinics of four hospitals. According to the results of more than 3000 measurements, they indicated that there was a significant difference in the failure rates between visual evaluation and ATP or microbiological counts, but lack of any significant difference in failure rates between ATP and microbiological counts. They evaluated $\geq 500$ RLU in the ATP bioluminescence method, and $\geq 2.5 \mathrm{CFU} / \mathrm{cm}^{2}$ in microbiological measurements as uncleanliness. In light of these results, they concluded that visual evaluation is not a reliable indicator of surface cleaning or cleaning efficiency. They stated that there were concerns about surface cleaning standards obtained after cleaning in hospitals ${ }^{[14]}$.

In the study where Sherlock et al. compared visual assessment, ATP measurement, microbiological evaluation and the presence of methicillin-resistant Staphylococcus aureus for the control of surface cleanliness, and indicated accuracy rates which met the level of 'acceptable cleanliness' as $93.3 \%, 71.5 \%, 92.1 \%$ and $95 \%$, respectively. Visual assessment alone did not always provide a meaningful measure of surface cleaning or cleaning efficiency. We see that ATP measurements are taken as a zigzag sampling on a surface of $10 \times 10 \mathrm{~cm}^{2}$ and they accepted $500 \mathrm{RLU}$ as a standard criterion ${ }^{[15]}$.

Lewis et al. ${ }^{[16]}$ also compared the ATP bioluminescence method, microbiological evaluation and visual examination in their study. Although many other studies accepted $500 \mathrm{RLU}$ as a criterion for unsuccessful cleaning, they advocated $250 \mathrm{RLU}$ instead. In general, they stated that it is more difficult to associate these reference values with the risk of infection and to isolate pathogens from the environment. They indicated that the ATP method measures only the organic residue on the surface, while microbiological methods measure the number of living organisms found on the surface and that the correlation between the two methods is difficult to reveal. 
In our study, we used the ATP bioluminescence method to check whether the surfaces that we consider to be clean are really clean and we used $250 \mathrm{RLU}$, which we consider to be a more sensitive limit value for cleanliness. As a limiting factor of our study, we can say that only a limited number of measurements has been performed.

\section{Conclusion}

In conclusion, we think that the ATP bioluminescence method may be effective in addition to visual evaluations in the supervision of environmental cleanliness, especially in hospitals and intensive care units.

Ethics Committee Approval: University of Health Sciences, Fatih Sultan Mehmet Health Application Research Center (30.01.2018/17073117-050.99).

Peer-review: Externally peer-reviewed.

Authorship Contributions: Concept: A.Y.A., S.Ö., A.E.A., S.A., G.T., C.A.; Data Collection or Processing: A.Y.A., S.Ö., S.A., A.E.A.; Analysis or Interpretation: A.Y.A., S.A., G.T., C.A.; Literature Search: A.Y.A., S.Ö., G.T., C.A.; Writing: A.Y.A., S.Ö., A.E.A., S.A., G.T., C.A.

Conflict of Interest: None declared.

Financial Disclosure: The authors declared that this study received no financial support.

\section{References}

1. Griffith CJ, Cooper RA, Gilmore J, Davies C, Lewis M. An evaluation of hospital cleaning regimes and standards. J Hosp Infect 2000;45:19-28. [CrossRef]

2. Amodio E, Dino C. Use of ATP bioluminescence for assessing the cleanliness of hospital surfaces: a review of the published literature (1990-2012). J Infect Public Health 2014;7:92-8.

3. Zambrano AA, Jones A, Otero P, Ajenjo MC, Labarca JA. Assessment of hospital Daily cleaning practices using ATP bioluminescence in a developing country. Braz J Infect Dis 2014; 18:675-7. [CrossRef]

4. Al-Hamad A, Maxwell S. How clean is clean? Proposed methods for hospital cleaning assessment. J Hosp Infect 2008;70:328-34. [CrossRef]

5. Mitchell BG, Farrington A, Allen M, Gardner A, Lisa Hall, Barnett
AG, et.al. Variation in hospital cleaning practice and process in Australian hospitals: A structured mapping exercise. Infection, Disease \& Health 2017;22:195-202. [CrossRef]

6. Nante N, Ceriale E, Messina G, Lenzi D, Manzi P. Effectiveness of ATP bioluminescence to assess hospital cleaning:a review. J Prev Med Hyg 2017;58:E177-E183.

7. Carling PC, Von Beheren S, Kim P, Woods C; Healthcare Environmental Hygiene Study Group. Intensive care unit enviromental cleaning: an evaluation in sixteen hospital using a novel assessment tool. J Hosp Infect 2008;68:39-44. [CrossRef]

8. Aytaç SA, Mercanoğlu B, Özbaş ZY. Tampon Çözeltide İmmunomanyetik Ayırma ve ATP Biyolüminesans Yöntemler ile Escherichia Coli 0157:H7 Sayımı.Türk Hij Den Biyol Derg 2001;58:49-52.

9. Turantaş F. ATP Biyolüminesans Yöntemi ve Gıda Mikrobiyolojisindeki Uygulamaları. Gıda 1996;21:331-5.

10. Huang YS, Chen YC, Chen ML, Cheng A, Hung IC, Wang JT, et al. Comparing visual inspection, aerobic colony counts, and adenosine triphosphate bioluminescence assay for evaluating surface cleanliness at a medical center. Am J Infect Control 2015;43:882-6. [CrossRef]

11. Lewis BD, Spencer M, Rossi PJ, Lee CJ, Brown KR, Malinowski $M$, et. al. Assessment of an innovative antimicrobial surface disinfectant in the operating room environment using adenosine triphosphate bioluminescence assay. Am J Infect Control 2015;43:283-5. [CrossRef]

12. Richard RD, Bowen TR. What Orthopaedic Operating Room Surfaces Are Contaminated With Bioburden? A Study Using the ATP Bioluminescence Assay. Clin Orthop Relat Res 2017;475:1819-24. [CrossRef]

13. Aycicek H, Oguz U, Karci K. Comparison of results of ATP bioluminescence and traditional hygiene swabbing methods for the determination of surface cleanliness at a hospital kitchen. Int J Hyg Environ Health 2006;209:203-6. [CrossRef]

14. Cooper RA, Griffith CJ, Malik RE, Obee P, Looker N. Monitoring the effectiveness of cleaning in four British hospitals. Am J Infect Control 2007;35:338-41. [CrossRef]

15. Sherlock O, O'Connell N, Creamer E, Humphreys H. Is it really clean? An evaluation of the efficacy of four methods for determining hospital cleanliness. J Hosp Infect 2009;72:140-6.

16. Lewis T, Griffith C, Gallo M, Weinbren M. A modified ATP benchmark for evaluating the cleaning of some hospital environmental surfaces. J Hosp Infect 2008;69:156-63. [CrossRef] 